\title{
Chapter 9 \\ The Role of Multilateral Agencies and Development Banks
}

This chapter concentrates on multilateral and development agencies, either located in Africa or pursing activities in the continent. The main objective is to understand what are their role in the financing of clean energy access in sub-Saharan Africa.

The chapter primarily targets professionals collaborating with development agencies as well as public administrations of the countries involved in their management.

It starts by presenting the inclusion of environmental considerations within those agencies, in addition to the historical objective to address social concerns as well as market failures. Moreover, this chapter aims at going beyond direct investments made by those institutions. Even though direct investments are crucial to bridge the financing gap associated with clean energy access, complementary solutions are needed to attract private capital at scale in this sector. Thanks to their international network and reputation, multilateral and development agencies have the potential to play an important role in this crucial development matter. Therefore, additional solutions are explored, such as advisory services and technical assistance (targeting public agencies, project developers and capital providers), stakeholder engagement, as well as mobilization tools to attract private financial actors.

Finally, this chapter ends with a proposal of business model evolution for multilateral and development agencies, including (i) the integration of complementary activities to attract private capital, (ii) the support of the creation of an enabling business and investment environment, and (iii) the mitigation of potential associated barriers to implementation. 
Multilateral agencies and development banks are national, bi- and multilateral development institutions whose original mission is to spur economic development and alleviate poverty, by providing advisory services, technical assistance and funding to the public and private sectors.

In the past decades, many multilateral agencies and development banks have started to link social and economic objectives with sustainability and environmental concerns. Indeed, several institutions announced their willingness to stop or limit their financing in coal, oil and gas projects, align their activities with the Paris Agreement and back initiatives with beneficial impact on the climate and the environment (Boston University et al., 2020).

The involvement of multilateral agencies and development banks in clean energy initiatives may increase confidence among investors thanks to their reputation and credibility as well as regional presence and extensive experience. Moreover, their assistance to member countries allows senior claims on public authorities and a high level of influence. Accordingly, they have a critical role to play in the financing of the access to clean energy in sub-Saharan Africa and are uniquely positioned to pave the way for the private sector.

In order to tackle the energy access challenge across the region, multilateral agencies and development banks have different means of action at their disposal as follows:

- Capacity building and technical assistance

- Direct investments

- Mobilisation tools

- Stakeholder engagement and management.

\subsection{Capacity Building, Technical Assistance and Advisory Services}

\subsubsection{Public Sector}

Those services can target various public actors, including policymakers, regulators, rural energy agencies and public financial institutions. They aim at assisting public authorities in creating an enabling business climate for clean energy initiatives, by lowering market and financial barriers that prevent private investments.

Multilateral agencies and development banks can support governments in establishing political stability as well as clear policies and regulations, harmonised with national energy roadmaps. They may also provide assistance in the design and implementation of cost-effective and socially beneficial public measures and help phase out counterproductive instruments such as fossil fuel subsidies. Through the expertise of multilateral agencies and development banks, public authorities can elaborate stable and clear legal and regulatory frameworks, with a long-term vision and ambitious targets, tailored to country-specific challenges and opportunities. 
Moreover, multilateral agencies and development banks can assist governments in overcoming the governance gap as well as in improving management capabilities and technical skills in state-owned companies such as public power utilities. Furthermore, they may participate in the design of bidding mechanisms as well as the development of pipeline facilities and project evaluation tools, in order to foster funding processes and financial closure.

\subsubsection{Project Developers}

Multilateral agencies and development banks can support project developers in activities such as feasibility studies, procurement processes, financial structuring and due diligence preparation, as well as economic, social and environmental impact assessment. Moreover, they may assist promising projects in the participation of tendering and bidding processes. This increases the availability of high-quality and investment-ready projects and helps establishing dynamic and competitive industries.

\subsubsection{Financial Institutions and Capital Providers}

Multilateral agencies and development banks can also provide technical assistance to private and public investors in order to increase their willingness and capacities to invest in the clean energy sector. They can raise awareness regarding financial mechanisms, deal structuring and risk assessment tools aimed at fostering investments in specific projects and companies. Finally, they can support local currency financing, by facilitating access to affordable capital for public and private domestic financial institutions and providing cross-currency swap ${ }^{1}$ to country members.

\subsection{Direct Investments}

Compared to other financial institutions, multilateral agencies and development banks have a different attitude regarding investments as they are expected to be profitable but without the necessity to adopt a profit-maximising approach. Moreover, they face less financial and regulatory restrictions than other commercially oriented investors, allowing more flexibility as well as longer investment horizons. Nevertheless, their investing activities are constrained by the importance of maintaining a high credit rating, primordial to ensure credibility and gain access to affordable capital on international financial markets.

\footnotetext{
${ }^{1}$ Money provided without exchange risk for a predefined period of time to members.
} 
Direct investments realised by multilateral agencies and development banks should have the objective to improve the competitiveness and attractiveness of clean energy initiatives that are beyond private investors' risk appetites. In addition, the allocation of capital shall be strategic and targeted towards underinvested sectors and specific development stages, such as emerging technologies, greenfield projects or power transmission and distribution activities.

Because their financial resources are limited, investment activities of multilateral agencies and development banks should not enter in competition with the private sector nor overcompensate for the risks taken. They might even disengage when investment opportunities are mature enough, in order to free up their resources and avoid crowding out private capital. Accordingly, it is important to determinate whether an investment opportunity requires public, private or blended financing, ensuring the most effective use of the available capital.

By providing financing to clean energy initiatives, multilateral agencies and development banks reinforce the confidence of investors and contribute to the building of a solid track record of successful projects with improved risk-reward profiles. As such, they offer the opportunity to catalyse private capital in key sectors providing positive externalities and help meet investors' requirements.

In addition, multilateral agencies and development banks can create attractive investment opportunities for investors that are reluctant to take on construction and development risks or be the first movers into new and unmatured markets, by investing at early development stages. This may support the mobilisation of capital coming from institutional investors, being typically large-scale and risk-adverse capital providers.

Multilateral agencies and development banks use a broad range of financial instruments and structures, such as concessional financing, ${ }^{2}$ equity investing, traditional loans and green bonds, as well as special-purpose investment vehicles, credit lines and liquidity facilities. In addition, they often make use of blended finance and risksharing mechanisms like syndicated loans, in which they may act as lead investor to reinforce confidence and increase private involvement.

\subsection{Mobilisation Tools}

In addition to investing activities, multilateral agencies and development banks are increasingly using other mechanisms to improve the attractiveness of investment opportunities and mobilise private capital.

Mainly through to their close relations with governments of member's countries, multilateral agencies and development banks have a competitive advantage in covering certain risks and are therefore uniquely positioned to provide guarantee instruments. In particular but without limitation, they can cover political, credit and

\footnotetext{
${ }^{2}$ Including grants, subsidies, soft loans, first loss-capital, junior/subordinated debt.
} 
counterparty risks when public authorities do not own the necessary resources and/or credibility to do so, thus improving investors' confidence.

Regarding the currency risk, the private sector may be reluctant to provide mechanisms to hedge less-traded currencies. Multilateral agencies and development banks can fill this gap by fostering local financing ${ }^{3}$ and establishing foreign exchange liquidity facilities to address the high-cost issue related to hedging instruments.

As an example, the Currency Exchange Fund ( $\left.\mathrm{TCX}^{4}\right)$ was created in 2007 to offer solutions to manage currency risk in developing and frontier markets. It consists of financial mechanisms (swaps and forward contracts) enabling TCX's investors to provide loan financing in over 70 currencies, shifting the foreign exchange risk to the fund. Capital providers are, thus, protected from currency volatility. This initiative was funded mainly by multilateral agencies and development banks and aims at providing access to currency protection to a wider range of market participants (GOGLA, n.d.).

Moreover, multilateral agencies and development banks can support the development of local capital markets in order to facilitate the use of secondary financial markets, derivative products and green bonds. Additionally, they can work closely with the banking sector to expand the range of available financial products and risk mitigation tools emanating from private actors, as well as build an inclusive financial sector fostering access to affordable capital for consumers and enterprises.

Finally, their local presence and in-house expertise provide multilateral agencies and development banks with a comprehensive understanding of the investment environment. Thus, it offers the possibility to develop new and tailored risk mitigation tools targeting unaddressed investment barriers. This task requires consultation and engagement of all relevant stakeholders involved in the clean energy access challenge.

\subsection{Stakeholder Engagement and Management}

In order to take adequate actions and respond to the needs of different private and public actors, it is important to increase cooperation and dialogue among stakeholders. Thanks to their intensive network and understanding of the sub-Saharan African energy access challenge, multilateral agencies and development banks can ensure coordination and strengthen relationships between parties. In addition, they may increase the commitment of core stakeholders to national energy strategies and stimulate their participation in addressing development concerns.

Moreover, multilateral agencies and development banks can share relevant information and best practices with market players, increasing awareness on risk mitigation tools and supporting better-informed investment decisions.

Finally, multilateral agencies and development banks are well-positioned to promote project bundling, cross-border collaboration and the integration of regional

\footnotetext{
${ }^{3}$ Using for instance non-performance buyout and third-party collateralisation.

${ }^{4}$ For more information: https://www.tcxfund.com/about-the-fund/.
} 
power markets, thus allowing economies of scale as well as facilitating access to international finance and risk mitigation mechanisms.

\subsection{Business Model Evolution}

The role multilateral agencies and development banks is evolving, shifting from a focus on grant-based development assistance to an approach driven by private sector development and involvement. In addition, those institutions have to ensure that collaboration is strengthened and their activities are not distorting markets and/or competing with other key stakeholders.

Traditionally, multilateral agencies and development banks have focused on addressing market failures and providing capital to projects, enterprises and financial intermediaries. In order to achieve SDG 7, more actions to mobilise private investments as well as an increasing presence in riskier markets are required, without compromising financial viability. Accordingly, an extension of multilateral agencies and development banks' focus is needed to address investment barriers and foster the allocation of funds towards the greatest economic, social and environmental challenges of our time, such as energy poverty. A new approach needs to be adopted, allowing the adaptation to new and risker contexts as well as complementing activities of other market participants.

Multilateral agencies and development banks need to use their resources to create an attractive investment environment for private capital. This requires a transition towards a wider use of risk mitigation and mobilisation tools, effective collaboration with public and private players, as well as stronger support to capacity building and the development of financial markets.

To effectively do so, multilateral agencies and development banks need to

- Understand what hampers capital allocation in the clean energy sector

- Align action with countries' targets, needs and programs

- Raise awareness around mobilisation tools, internally and externally.

Moreover, a different allocation of multilateral agencies and development banks' resources necessitates a reorientation of their internal culture, by increasing awareness and building capacity around mobilisation and risk mitigation tools. It does not mean those institutions should stop direct financing, but rather continue investing activities in sectors in which private capital is not available, while expanding actions aimed at creating an attractive business environment.

However, such changes do not come overnight and may face the following implementation barriers:

- Cultural biases against risk mitigation actions as well as engagement with the private sector.

- Donors' interests are dominating operations and might not be aligned with a reorientation of activities.

- Risk mitigation tools generate generally less revenues than direct investments. 
Table 9.1 Differences and complementarities between development and commercial finance

\begin{tabular}{l|l}
\hline Development finance & Commercial finance \\
\hline Development mandate & Commercial mandate \\
\hline Longer-term lending & Shorter-term lending \\
\hline Profit seeking & Profit maximising \\
\hline Economic rates of return & Financial rates of return \\
\hline Public-private partnerships & Public-private partnerships \\
\hline Capacity building & - \\
\hline Project preparation & - \\
\hline
\end{tabular}

Source Authors' elaboration, based on Boston University et al. (2020)

Part of those issues is related to internal incentives. Indeed, investment teams within multilateral agencies and development banks are sometimes rewarded based on the amount of money invested, rather than on the impact generated. In addition, some pressure exists to maintain high credit rating.

In order to overcome those challenges, multilateral agencies and development banks need innovative financial structures such as special-purpose vehicles (SPVs) where risk is contained and separated from originators. Moreover, they need to improve the measurement and transparency of their direct and indirect impacts and ensure that the development results are not double counted. Finally, new benchmarks, metrics and key performance indicators (KPIs) are needed to engage the entire internal workforce.

Table 9.1 presents the main differences and complementarities between development and commercial finance.

\section{References}

Boston University, University of Pretoria, The Southern Africa Development Community Development Finance Resource Center, The Development Bank of Southern Africa. (2020). Expanding renewable energy for access and development: The role of development finance institutions in Southern Africa, 2020. Global Development Policy Center, Boston University

GOGLA. (n.d.). The currency exchange fund (TCX). Retrieved September 27, 2020, from https:// www.gogla.org/about-us/members/the-currency-exchange-fund-tcx 
Open Access This chapter is licensed under the terms of the Creative Commons Attribution 4.0 International License (http://creativecommons.org/licenses/by/4.0/), which permits use, sharing, adaptation, distribution and reproduction in any medium or format, as long as you give appropriate credit to the original author(s) and the source, provide a link to the Creative Commons license and indicate if changes were made.

The images or other third party material in this chapter are included in the chapter's Creative Commons license, unless indicated otherwise in a credit line to the material. If material is not included in the chapter's Creative Commons license and your intended use is not permitted by statutory regulation or exceeds the permitted use, you will need to obtain permission directly from the copyright holder.

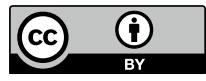

